\section{A) Check for updates}

Cite this: Dalton Trans., 2022, 51 1206

Received 28th September 2021, Accepted 25th November 2021 DOI: $10.1039 / \mathrm{d} 1 \mathrm{dt} 03296 \mathrm{~h}$ rsc.li/dalton

\title{
Influence of the spatial distribution of copper sites on the selectivity of the oxygen reduction reaction $\uparrow$
}

\author{
N. W. G. Smits, ${ }^{a}$ D. Rademaker, ${ }^{a}$ A. I. Konovalov, (D) ${ }^{a}$ M. A. Siegler ${ }^{b}$ and \\ D. G. H. Hetterscheid (D) *a
}

\begin{abstract}
Moving towards a hydrogen economy raises the demand for affordable and efficient catalysts for the oxygen reduction reaction. Cu-bmpa (bmpa = bis(2-picolyl)amine) is shown to have moderate activity, but poor selectivity for the 4-electron reduction of oxygen to water. To enhance the selectivity towards water formation, the cooperative effect of three Cu-bmpa binding sites in a single trinuclear complex is investigated. The catalytic currents in the presence of the trinuclear sites are lower, possibly due to the more rigid structure and therefore higher reorganization energies and/or slower diffusion rates of the catalytic species. Although the oxygen reduction activity of the trinuclear complexes is lower than that of mononuclear $\mathbf{C u}$-bmpa, the selectivity of the copper mediated oxygen reduction was significantly enhanced towards the 4-electron process due to a cooperative effect between three copper centers that have been positioned in close proximity. These results indicate that the cooperativity between metal ions within biomimetic sites can greatly enhance the ORR selectivity.
\end{abstract}

\section{Introduction}

The development and storage of renewable energy are crucial to limit our fossil fuel consumption while sustaining the demand for energy. Within such a hydrogen society, fuel cell technology plays a central role. ${ }^{1-3}$ The limiting factor of such systems lies with the oxygen reduction reaction (ORR), which involves the redistribution of four protons and four electrons with a simultaneous cleavage of the $\mathrm{O}-\mathrm{O}$ bond. ${ }^{4}$ This leads to a complex reaction mechanism with numerous intermediates. ${ }^{5}$ Consequently, a significant overpotential is required for ORR catalysis, which results in a substantial loss of energy. For the ORR, platinum catalysts are typically employed due to their relatively low overpotential, which is still quite substantial with roughly $400 \mathrm{mV} .^{6,7}$ Moreover, platinum is not a sufficiently abundant material for large scale applications. This raises the demand for catalysts based on more affordable materials to drive the ORR at a low overpotential.

Inspiration for the design of efficient catalysts that catalyse the ORR at a low overpotential and are based on abundant

\footnotetext{
${ }^{a}$ Leiden Institute of Chemistry, Leiden University, P.O. box 9502, 2300 RA Leiden, The Netherlands. E-mail: d.g.h.hetterscheid@chem.leidenuniv.nl

${ }^{b}$ Department of Chemistry, Johns Hopkins University, 3400 N. Charles Street, Baltimore, MD 21218, USA

$\dagger$ Electronic supplementary information (ESI) available. CCDC 2099322 for $\mathrm{Cu}_{3}$ L1. For ESI and crystallographic data in CIF or other electronic format see DOI: $10.1039 / \mathrm{d} 1 \mathrm{dt} 03296 \mathrm{~h}$
}

materials can be found in natural systems, particularly in redox metalloenzymes. A prime example is the multicopper enzyme laccase, which belongs to a family of oxidases and can be found in a variety of natural sources. ${ }^{8,9}$ This enzyme couples the oxidation of an organic substrate near a mononuclear $\mathrm{Cu}$ site to ORR catalysis at a trinuclear $\mathrm{Cu}$ cluster. ${ }^{10,11}$ Electrochemical studies on immobilized laccase have shown that the enzyme catalyzes the ORR close to the equilibrium potential. ${ }^{12-14}$ However, laccase has a low overall efficiency for the ORR in fuel cells due to the instability of the enzyme under fuel cell conditions and slow electron transfer to the active site. ${ }^{15}$ Nevertheless, the active site of laccase represents an interesting starting point for the development of new $\mathrm{Cu}$ based molecular catalysts for the ORR that operate with a low overpotential and a high efficiency.

Mononuclear $\mathrm{Cu}$ complexes have been explored to catalyze the ORR. ${ }^{16-34}$ Additionally, several dinuclear complexes have been investigated to induce a cooperative effect during ORR catalysis. ${ }^{35-38}$ We have recently shown that the mononuclear complex $[\mathrm{Cu}(\mathrm{tmpa})(\mathrm{solv})]^{+}$(Cu-tmpa, tmpa $=$tris(2-picolyl) amine) shows exceptionally high ORR catalytic performance with a turn-over frequency (TOF) of almost 2 million per second. ${ }^{19,39}$ We showed that the reduction of oxygen to water proceeds via a two-step process in which hydrogen peroxide is formed as an obligatory intermediate product. ${ }^{40}$ The complexes Cu-terpy and Cu-bmpa, which showed a lower denticity and flexibility of the ligand framework than Cu-tmpa, undergo the ORR with a lower activity and with a lower selectivity 
towards water (terpy $=2,2^{\prime}: 6^{\prime}, 2^{\prime \prime}$-terpyridine; bmpa = bis(2-pyridylmethyl)amine). ${ }^{20}$ Since $\mathrm{H}_{2} \mathrm{O}_{2}$ is damaging to fuel cell systems, the production of this compound is an unwanted side-reaction.

In laccase, the cooperativity of the $\mathrm{Cu}$ ions in the trinuclear cluster results in the reduction of oxygen to water, without the formation of $\mathrm{H}_{2} \mathrm{O}_{2}$ as an intermediate product. Inspired by laccase, several trinuclear $\mathrm{Cu}$-based molecular catalysts have been reported for the ORR, of which most are based on ligands bearing alkylamine and pyridylalkyl-amine functional groups. ${ }^{41-52}$ In early reports, only oxygen binding and reductive cleavage were investigated. ${ }^{41,42,44}$ Later, the ORR activity of several trinuclear $\mathrm{Cu}$ complexes was investigated. ${ }^{46-48}$ These studies were carried out either by using organic solvents in the presence of sacrificial reagents, ${ }^{47}$ or by dropcasting the catalyst as part of carbon paste onto electrodes. Due to the very flexible and dynamic linkers employed to tether the copper sites together, it remains difficult to assess whether under these operative conditions these structures truly function as trinuclear sites. ${ }^{44,47}$ Consequently, the reported results have been rather inconclusive thus far. Inspired by the active site of laccase, and lessons learned in the previous studies, our study here focuses on a structurally rigid triethylbenzene node that forces all three copper sites linked to the remaining aromatic positions in close proximity to each other (Fig. 1).

Copper complexes with the $\mathbf{L} 1$ and $\mathbf{L} 2$ ligands have previously been reported for their reactivity with oxygen in organic solution and for their ability to cleave DNA via hydrolysis. ${ }^{53-56}$ In these studies, the crystal structures of these trinuclear complexes indicated that in $\mathbf{C u}_{3} \mathbf{L} 2$ all three copper sites are forced into close proximity due to steric repulsion between neighboring groups on the aromatic node, while in $\mathbf{C u}_{3} \mathbf{L 1}$ only two $\mathrm{Cu}$ centers will lie in close proximity. ${ }^{55,56} \mathrm{We}$ report here that $\mathbf{C u}_{3} \mathbf{L} \mathbf{1}$ has a similar selectivity for $\mathrm{H}_{2} \mathrm{O}$ compared to the parent mononuclear complex Cu-bmpa, and that the close proximity of the three $\mathrm{Cu}$ ions in $\mathrm{Cu}_{3} \mathbf{L} 2$ induces high selectivity for the selective formation of $\mathrm{H}_{2} \mathrm{O}$.

\section{Results}

\section{Characterization of the trinuclear compounds}

Synthesis. The $\mathbf{L} 1$ and $\mathbf{L} 2$ ligands were synthesized via adopting the reported procedures (ESI $2 \dagger$ ). ${ }^{55}$ The consecutive complexation of the ligands with three equivalents of $\mathrm{Cu}(\mathrm{OTf})_{2}$
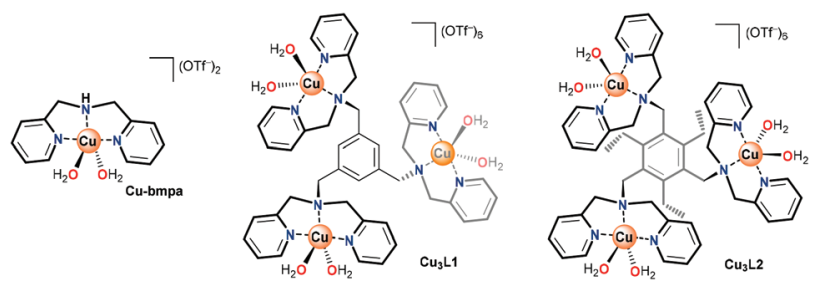

Fig. 1 Structures of Cu-bmpa and trinuclear $\mathrm{Cu}$ complexes $\mathrm{Cu}_{3} \mathrm{~L} 1$ and $\mathrm{Cu}_{3} \mathrm{~L} 2$. resulted in the formation of the trinuclear copper complexes $\mathrm{Cu}_{3} \mathrm{~L} 1$ and $\mathrm{Cu}_{3} \mathrm{~L} 2$ (Fig. S1†). Both $\mathrm{Cu}_{3} \mathrm{~L} 1$ and $\mathrm{Cu}_{3} \mathrm{~L} 2$ were characterized by UV-Vis spectroscopy and superconducting quantum interference device (SQUID) magnetometry. The purity of the samples was confirmed by elemental analysis, while UV-Vis stability studies also indicated that both complexes are stable in an aqueous $\mathrm{pH} 7$ phosphate buffer for at least two days (Fig. $\mathrm{S} 2 \dagger$ ).

\section{Single crystal X-ray crystallography}

Slow vapour diffusion of $\mathrm{Et}_{2} \mathrm{O}$ into a concentrated solution of $\mathrm{Cu}_{3} \mathbf{L} 1$ in acetone at $279 \mathrm{~K}$ resulted in single crystals which were suitable for X-ray crystallography (Fig. 2 and ESI $3 \dagger$ ).

The crystal structure clearly shows an asymmetric distribution of the three Cu-bmpa sites relative to the benzene plane. A similar distribution was published for the crystal structure of $\left[\mathbf{L 1}\left(\mathrm{CuCl}_{2}\right)_{3}\right]$ by Guo et al. in $2006,{ }^{56}$ who reported square pyramidal geometries for all three $\mathrm{Cu}^{\mathrm{II}}$ ions. In contrast, two of the three $\mathrm{Cu}^{\mathrm{II}}$ ions in the crystal structure of $\mathrm{Cu}_{3} \mathrm{L1}$ have an octahedral geometry due to the close proximity of triflate counter ions (Fig. 2b). The relatively short Cu1-O19 and Cu3-O13 bond distances of 2.691(3) and 2.650(3) A, respectively, suggest that the triflate counter ions are weakly coordinated to the two $\mathrm{Cu}$ centers.

For $\mathbf{C u}_{3} \mathbf{L} 2$, the various single crystals that were obtained during this study did not diffract well enough for X-ray structure determination. However, the crystal structure of $[\mathbf{L} 2$ $\left.\left(\mathrm{CuCl}_{2}\right)_{3}\right]$ has been reported by Anslyn et al. and showed closer proximity of the three Cu-bmpa sites to each other. ${ }^{55}$ All three sites are forced to the same side of the benzene plane due to the steric effect of the three ethyl substituents (Fig. 3).

\section{Magnetic properties}

To assess the strength of the spatial interaction of the three paramagnetic $\mathrm{Cu}^{\mathrm{II}}$ centers, the magnetic properties of complexes $\mathrm{Cu}_{3} \mathrm{~L} \mathbf{1}$ and $\mathrm{Cu}_{3} \mathbf{L} 2$ were investigated using a superconducting quantum interference device (SQUID). In Fig. 4, the inverse of the obtained paramagnetic susceptibility $\left(X_{\mathrm{p}}\right)$ is plotted versus temperature. To extract the exchange coupling constants $(J)$ between each pair of $\mathrm{Cu}^{\mathrm{II}}$ ions, the obtained magnetic data were fitted using the PHI software (ESI $4 \dagger$ ). ${ }^{57}$

For $\mathbf{C u}_{3} \mathbf{L 1}$, this resulted in three $J$-values, two of which were negligibly small suggesting virtually no magnetic coupling between two pairs of $\mathrm{Cu}^{\mathrm{II}}$ ions. The third constant amounted to $+23 \mathrm{~cm}^{-1}$ indicating ferromagnetic coupling (Fig. 5). ${ }^{58} \mathrm{In}$ order to be able to couple ferromagnetically, the $\mathrm{Cu}$ ions have to be in close proximity to each other which is consistent with the two $\mathrm{Cu}$ ions being on one side of the benzene plane and the third one to the other side of the ring as was observed in the acquired crystal structure. For $\mathbf{C u}_{3} \mathbf{L} 2$, the fitting returns one $J$ value of $+49 \mathrm{~cm}^{-1}$ confirming the symmetric distribution of the three $\mathrm{Cu}^{\mathrm{II}}$ sites as expected on the basis of the reported crystal structure for $\left[\mathbf{L} 2\left(\mathrm{CuCl}_{2}\right)_{3}\right]$ (Fig. 5). 

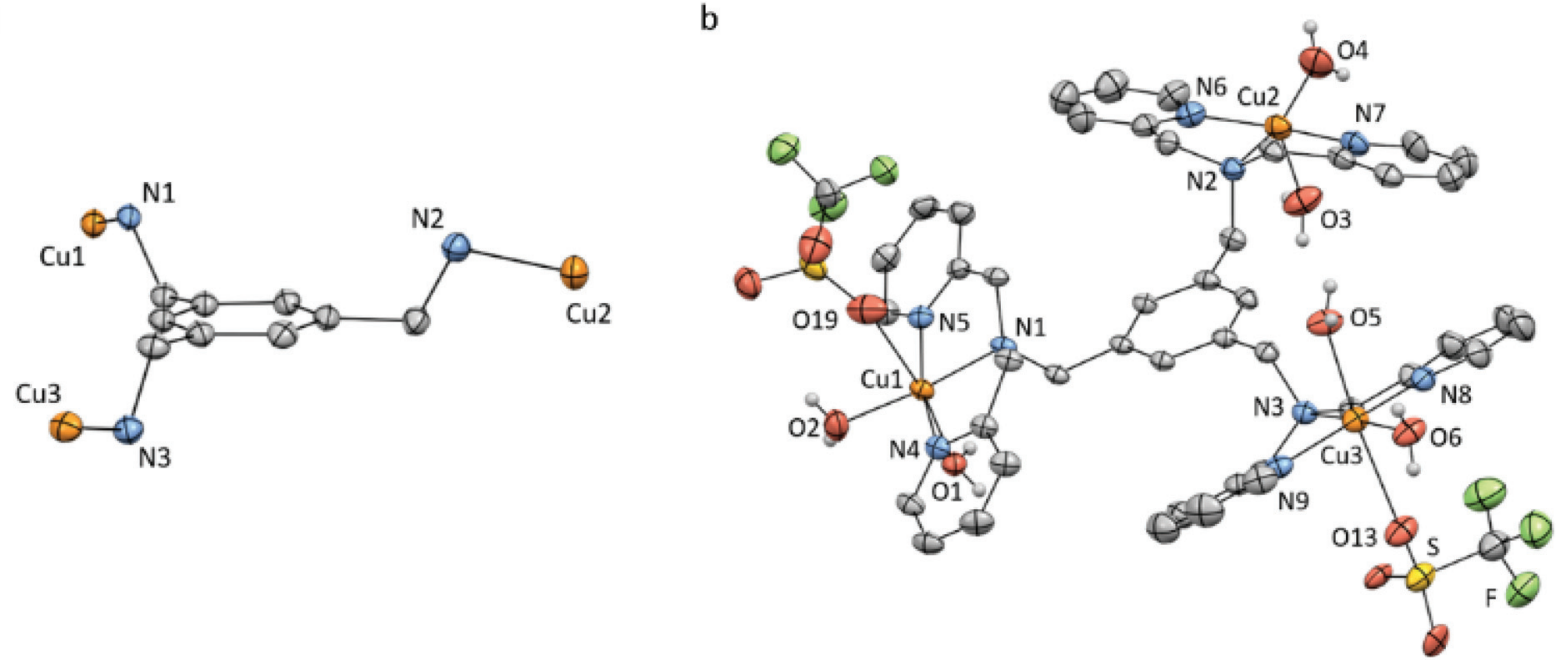

Fig. 2 Displacement ellipsoid plots (50\% probability level) of $\mathrm{Cu}_{3} \mathrm{~L} 1$ at 110 (2) K. (a) Orientation of the Cu ions relative to the benzene plane. (b) Full structure of $\mathrm{Cu}_{3} \mathrm{~L}$ 1. Lattice solvent molecules, four non-coordinating triflate ions, and all hydrogen atoms which are not part of the aqua ligands are omitted for clarity. Selected bond distances and angles are reported in ESI section $3 . \dagger$

a

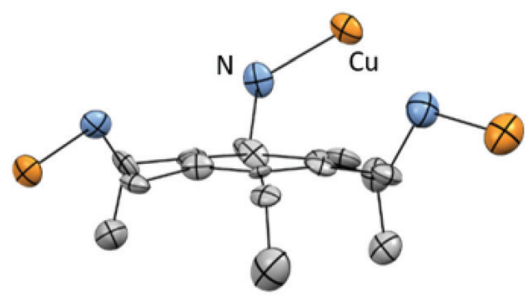

b

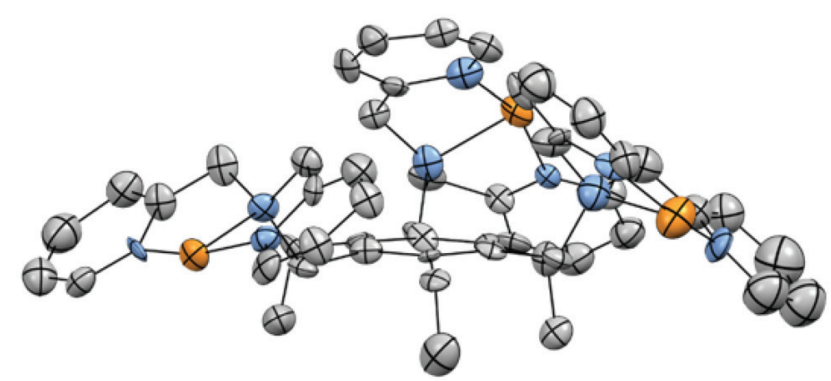

Fig. 3 Reported crystal structure of the cationic part of $\left[\mathrm{L}_{2}\left(\mathrm{CuCl}_{2}\right)_{3}\right]$ as determined by X-ray crystallography with displacement ellipsoids scaled at the $30 \%$ probability level. (a) Orientation of the $\mathrm{Cu}$ ions relative to the benzene plane. (b) All hydrogen atoms, lattice solvent molecules, and the chloride ions are omitted for clarity. Adapted with permission from Anslyn et al. Copyright (2002) American Chemical Society. ${ }^{55}$
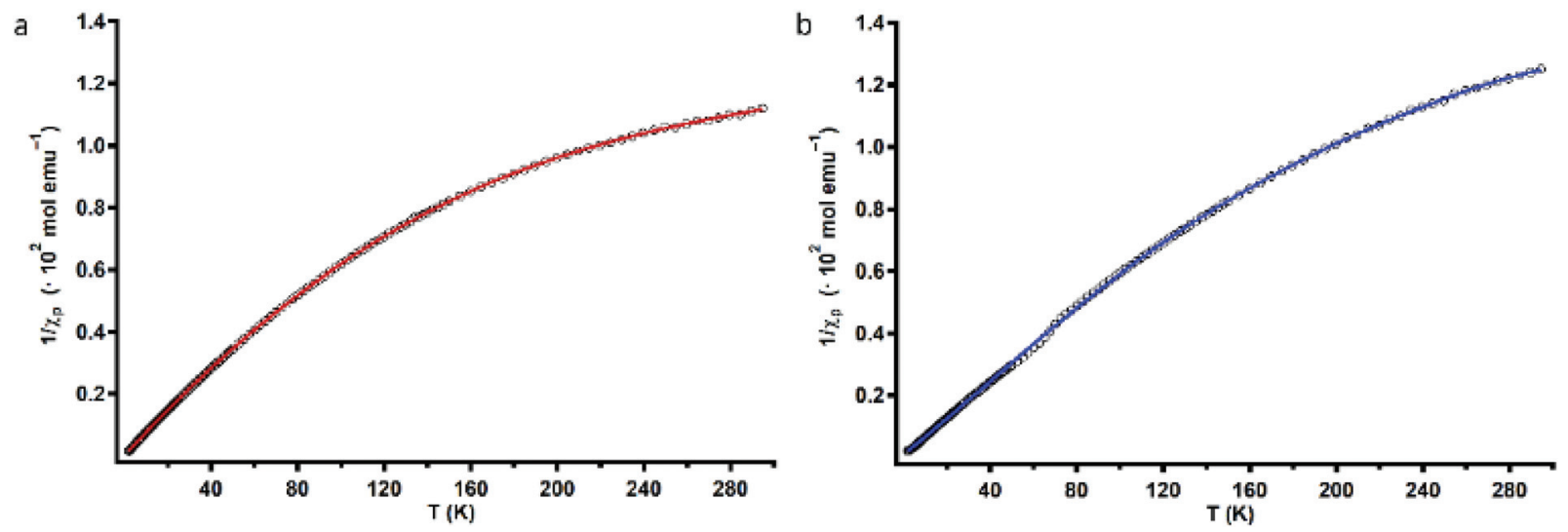

Fig. 4 Variable-temperature magnetic susceptibility plots of $\mathrm{Cu}_{3} \mathrm{~L} 1$ (a) and $\mathrm{Cu}_{3} \mathrm{~L} 2$ (b). Black circles depict the experimentally obtained data points, and red and blue lines correspond to the fitted data that were used to obtain magnetic exchange coupling constants $(\mathrm{J})$. 

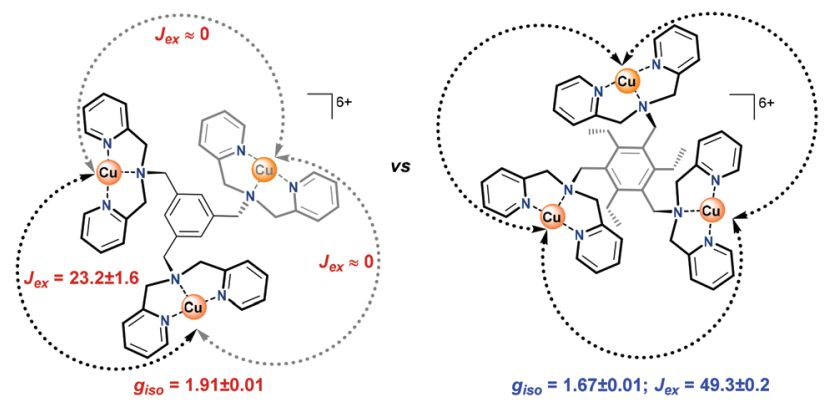

Fig. 5 Spatial distribution of the Cu-bmpa sites relative to the benzene plane for $\mathrm{Cu}_{3} \mathrm{~L} 1$ (left) and $\mathrm{Cu}_{3} \mathrm{~L} 2$ (right) as confirmed by the exchange coefficients obtained by fitting of the obtained magnetic data. Black arrows indicate ferromagnetic coupling and grey arrows indicate no magnetic coupling between the two corresponding copper ions.

\section{Structure in solution}

Although the X-ray and SQUID analysis confirm the structure in the solid phase, conversion to other conformers may still occur in solution. The structure of hexaethylbenzene and variations thereof have been extensively studied in solution in the past. Both computational and NMR studies showed that for hexaethylbenzene the up-down-up-down-up-down conformation of six substituents is the lowest conformer, with at least $3.46 \mathrm{kcal} \mathrm{mol}^{-1}$ energy difference to the next favorable geometry (i.e. up-down-down-up-down-down). ${ }^{59,60}$ Therefore, a large majority of the compounds adopts the alternating updown conformation. We anticipate that the even more bulkier Cu-bmpa substituent will not lower this energy difference between the various conformers, and therefore, it is expected that the alternating up-down conformation is also predominantly adopted by $\mathbf{C u}_{3} \mathbf{L} 2$ in solution. ${ }^{59-63}$ For $\mathbf{C u}_{3} \mathbf{L 1}$ the rotation of the Cu-bmpa substituents around the benzene node will be less prohibited due to the absence of the ethyl groups. Therefore, the distribution between the conformers is expected to be much more random for $\mathrm{Cu}_{3} \mathbf{L 1}$.

\section{Electrochemical behaviour of $\mathrm{Cu}_{3} \mathrm{~L} 1$ and $\mathrm{Cu}_{3} \mathrm{~L} 2$}

Redox couple under an argon atmosphere. The redox behavior of $\mathrm{Cu}_{3} \mathrm{~L} \mathbf{1}$ and $\mathrm{Cu}_{3} \mathrm{~L} 2$ was investigated by performing cyclic voltammetry (CV) measurements (Fig. 6). The acquired voltammograms for $\mathrm{Cu}_{3} \mathbf{L} \mathbf{1}$ and $\mathrm{Cu}_{3} \mathbf{L} \mathbf{2}$ show quite broad cathodic and anodic peaks which are located at a half-wave potential $\left(E_{1 / 2}\right)$ of 0.37 and $0.50 \mathrm{~V} v s$. the RHE, respectively. The peak-to-peak potential separation $\left(\Delta E_{\mathrm{p}}\right)$ amounts to $105 \mathrm{mV}$ for $\mathbf{C u}_{3} \mathbf{L 1}$ and to $90 \mathrm{mV}$ for $\mathbf{C u}_{3} \mathbf{L} 2$. These relatively large $\Delta E_{\mathrm{p}}$ values can be the result of the slow electron transfer and/or partial overlap of multiple electrochemical processes which have a lower redox potential than the preceding electrochemical step. ${ }^{64}$ The presence of an oxidative shoulder at more positive potential than the main oxidative process of $\mathbf{C u}_{3} \mathbf{L} \mathbf{1}$ supports the latter hypothesis.

Differential pulse voltammetry (DPV), and linear sweep voltammetry (LSV) were used to further pinpoint the redox behavior of $\mathbf{C u}_{3} \mathbf{L} \mathbf{1}$ and $\mathbf{C u}_{3} \mathbf{L}$ 2. In the latter experiment, a resting

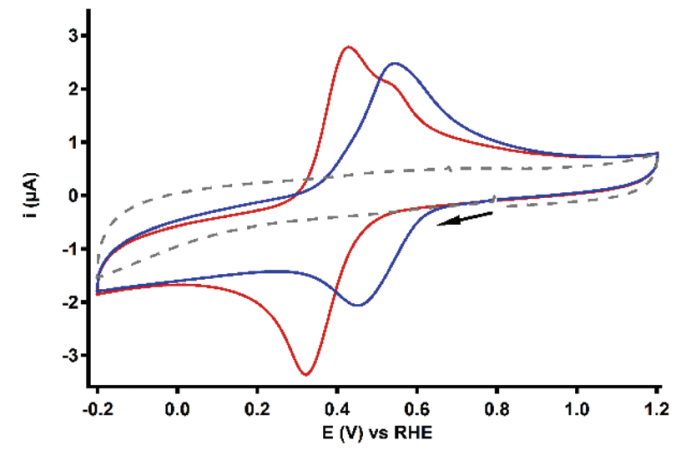

Fig. $6 \mathrm{CV}$ profiles of $0.1 \mathrm{mM} \mathrm{Cu} \mathrm{Cu}_{1}$ (red) and $\mathrm{Cu}_{3} \mathrm{~L} 2$ (blue). For both complexes, only the first scan of the measurement is depicted. The reference voltammogram in the absence of the complex is depicted as a grey dashed line. Conditions: $0.1 \mathrm{M} \mathrm{pH} 7$ PB, 1 atm Ar, r.t., GC WE, $100 \mathrm{mV} \mathrm{s}^{-1}$ scan rate.

potential is applied either at a high or low potential before the start of the LSV measurement to ensure that all copper sites are either in the $+\mathrm{II}$ or $+\mathrm{I}$ oxidation state at the start of the LSV experiment despite the slow electron transfer kinetics.

For $\mathrm{Cu}_{3} \mathbf{L 1}$, both anodic LSV and DPV measurements indicated the presence of two anodic peaks at 0.38 and $0.48 \mathrm{~V} v s$. the RHE (Fig. S4 $\dagger$ ). The separation of the broad anodic peak into multiple oxidative processes has previously been observed for $\left[\mathbf{L 1}\left(\mathrm{CuCl}_{2}\right)_{3}\right]$ by Zhao et al. ${ }^{56}$ who identified three individual anodic peaks in $0.1 \mathrm{M}$ aqueous $\mathrm{KCl}$. The observation of three separate anodic processes instead of two for $\mathbf{C u}_{3} \mathbf{L 1}$ might be an effect of the presence of a different electrolyte and other counter ions. The cathodic peak could not be resolved in separate reduction processes for $\mathbf{C u}_{3} \mathbf{L 1}$.

For $\mathbf{C u}_{3} \mathbf{L} 2$, a cathodic sweep resulted in a separation of the main cathodic peak into two distinct reductive processes at 0.46 and $0.17 \mathrm{~V} v s$. the RHE (Fig. S5 $\dagger$ ). Assuming the influence of the magnetic coupling of the $\mathrm{Cu}^{\mathrm{II}}$ ions on this separation, the initial reduction of one or two $\mathrm{Cu}^{\mathrm{II}}$ ions could result in a thermodynamically less favorable reduction of the other $\mathrm{Cu}^{\mathrm{II}}$ ion(s). Not only this electronic coupling, but also the structural changes upon reduction can cause a separation of the cathodic peak. ${ }^{65-68}$ Separation of both the cathodic and anodic peak has been reported for $\left[\mathrm{L} 2(\mathrm{CuX})_{3}\right](\mathrm{X}=\mathrm{Br}$ or I) in DCM by Kim et al. ${ }^{54}$ In contrast, the DPV of $\mathbf{C u}_{3} \mathbf{L} 2$ did not result in the separation of the main anodic peak into distinct processes.

\section{Oxygen reduction reaction catalysis}

The ORR behavior of $\mathbf{C u}_{3} \mathbf{L} \mathbf{1}$ and $\mathbf{C u}_{3} \mathbf{L} 2$ was investigated with $\mathrm{CV}$ under 1 atm $\mathrm{O}_{2}$. Under these conditions, the voltammograms of both complexes show a peak-shaped catalytic wave (Fig. 7). For Cu-bmpa, an $E_{\text {cat } / 2}$ value of $0.37 \mathrm{~V} v s$. the RHE has been reported with the notion that $E_{\text {cat } / 2}>E_{1 / 2}$ due to substrate depletion near the electrode. ${ }^{20}$ However, a relatively low $E_{\text {cat } / 2}$ value is observed for both $\mathbf{C u}_{3} \mathbf{L 1}$ and $\mathbf{C u}_{3} \mathbf{L} 2$, amounting to $0.37 \mathrm{~V}$ vs. the RHE for $\mathbf{C u}_{3} \mathbf{L} \mathbf{1}$ and $0.33 \mathrm{~V}$ vs. the RHE for $\mathrm{Cu}_{3} \mathbf{L} 2$. This means that $E_{\text {cat/2 }}$ is equal to the $E_{1 / 2}$ value for $\mathbf{C u}_{3} \mathbf{L} \mathbf{1}$ and lower than the $E_{1 / 2}$ value for $C_{\mathbf{u}_{3}} \mathbf{L} 2$. This suggests that the 

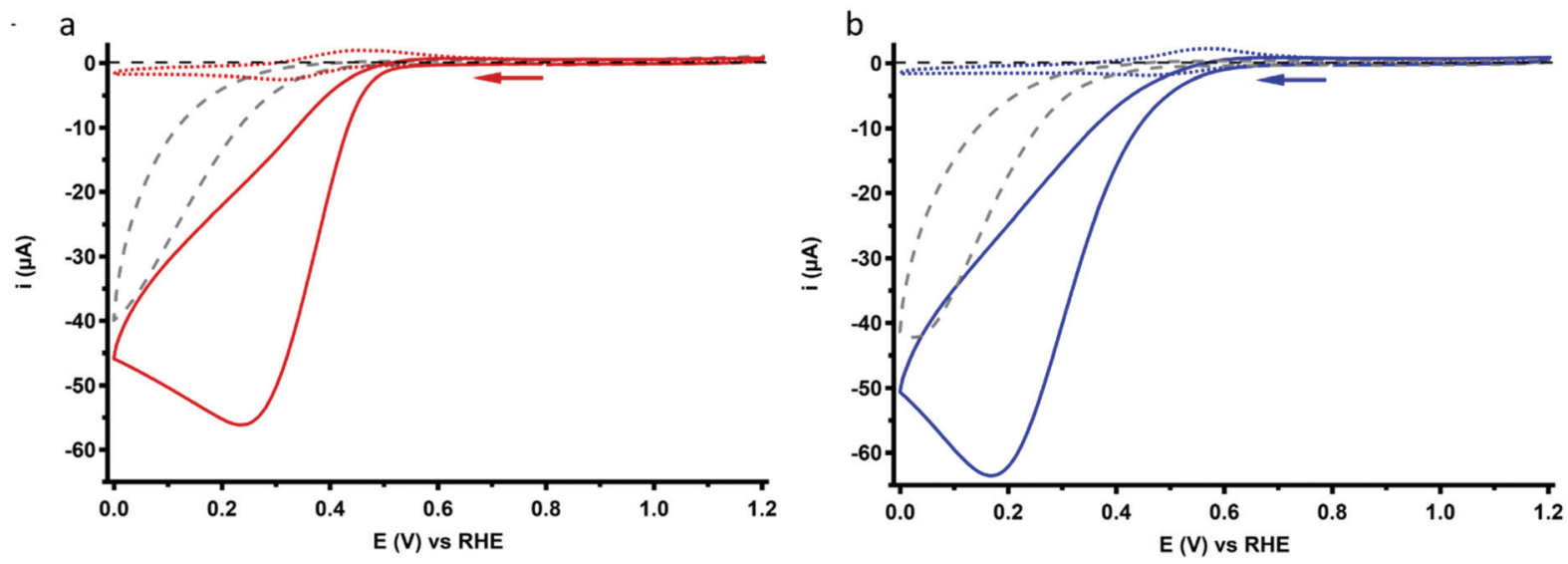

Fig. $7 \mathrm{CV}$ profiles of $0.1 \mathrm{mM} \mathrm{Cu}_{3} \mathrm{~L} 1$ (a) and $\mathrm{Cu}_{3} \mathrm{~L} 2$ (b) under $1 \mathrm{~atm} \mathrm{O}_{2}$ (solid lines) or $1 \mathrm{~atm}$ Ar (dotted lines). For both complexes, only the first scan of each measurement is depicted. The reference voltammogram in the absence of the complex under 1 atm $\mathrm{O}_{2}$ is depicted as a grey dashed line. Conditions: $0.1 \mathrm{M} \mathrm{pH} 7$ phosphate buffer, $293 \mathrm{~K}, \mathrm{GC} \mathrm{WE}, 100 \mathrm{mV} \mathrm{s}^{-1}$ scan rate.

rates for the oxygen reduction reaction are not much influenced by substrate depletion compared to Cu-bmpa.

\section{Active species homogeneity}

The homogeneity of the redox behavior of both $\mathbf{C u}_{3} \mathbf{L} \mathbf{1}$ and $\mathrm{Cu}_{3} \mathbf{L} 2$ was assessed by performing a scan rate dependence study. From the $i_{\mathrm{p}, \text { red }} v s . \nu^{1 / 2}$ plots depicted in Fig. S6, $\dagger$ a linear relationship is observed between the cathodic peak current and the square root of the scan rate for both $\mathrm{Cu}_{3} \mathrm{L1}$ and $\mathrm{Cu}_{3} \mathbf{L 2}$, which is in good agreement with a diffusive species (ESI 6.2†).

A deposition test with $\mathrm{CV}$ under $1 \mathrm{~atm} \mathrm{O}_{2}$ indicated that after 1 scan, an ORR active deposit was formed (ESI 7.1†). However, the activity of this deposition was significantly lower than that for the catalyst solution. Moreover, electrochemical quartz crystal microbalance (EQCM) experiments were performed to quantify the amount of complex that was deposited during a CV experiment (ESI 7.2 $\dagger$ ) which showed that only 7.0 and 8.8 pmol cm${ }^{-2}$ of $\mathbf{C u}_{3} \mathbf{L} \mathbf{1}$ and $\mathbf{C u}_{3} \mathbf{L} 2$ are deposited during one scan, respectively. Therefore, the effect of the deposit on the ORR catalysis during CV experiments was considered to be negligible.

\section{Product selectivity determination}

The product selectivity of the ORR catalyzed by $\mathbf{C u}_{3} \mathbf{L 1}$ and $\mathrm{Cu}_{3} \mathbf{L} 2$ was investigated using a setup with a rotating ring disk electrode (RRDE) ${ }^{20}$ This was done by performing LSV at the GC disk and chronoamperometry (CA) at the Pt ring while rotating the RRDE at a speed of 1600 RPM. For both $\mathbf{C u}_{3} \mathbf{L} \mathbf{1}$ and $\mathrm{Cu}_{3} \mathbf{L} 2$, LSV was performed between 1.0 and $-0.15 \mathrm{~V}$ vs. the RHE, while CA at the ring was performed at $1.2 \mathrm{~V} v s$. the RHE to be able to oxidize any $\mathrm{H}_{2} \mathrm{O}_{2}$ that is produced during ORR catalysis (Fig. 8). Since $\mathrm{H}_{2} \mathrm{O}_{2}$ is the product of the twoelectron ORR, the presence of the Pt ring enables the determination of the product selectivity of the catalyzed ORR (ESI $8.2 \dagger)$.

For the RRDE LSV measurements the ORR onset potential of $\mathbf{C u}_{3} \mathbf{L 1}$ and $\mathbf{C u}_{3} \mathbf{L 2}$ has been defined as the potential at

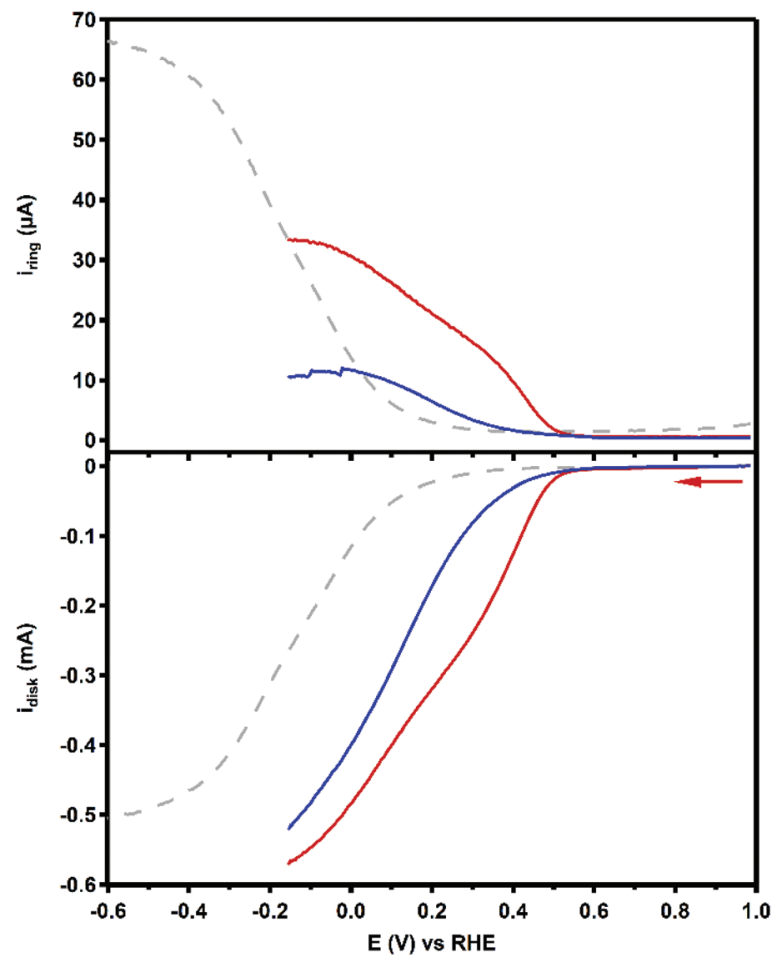

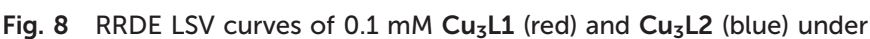
$1 \mathrm{~atm} \mathrm{O}_{2}$ at $1600 \mathrm{RPM}$. The reference voltammogram in the absence of the complex is depicted as a grey dashed line. Conditions: $0.1 \mathrm{M} \mathrm{pH} 7$ phosphate buffer, $293 \mathrm{~K}, \mathrm{GC}$ disk, Pt ring at $1.2 \mathrm{~V} v \mathrm{~s}$. RHE, $50 \mathrm{mV} \mathrm{s}^{-1}$ scan rate.

which $i_{\mathrm{c}} / i_{\mathrm{GC}}>3$, in which $i_{\mathrm{c}}$ is the disk current observed during ORR catalysis performed by the catalyst and $i_{\mathrm{GC}}$ is the disk current observed in the absence of the catalyst. ${ }^{1920}$ For $\mathrm{Cu}_{3} \mathrm{L1}$ and $\mathrm{Cu}_{3} \mathrm{~L} 2$, this onset potential is located at 0.55 and $0.52 \mathrm{~V} v s$. the RHE, respectively. Considering the reported ORR onset potential of $0.49 \mathrm{~V} v$ s. the RHE for Cu-bmpa, the overpotential for the ORR catalyzed by the trinuclear catalysts is 
slightly lower than the overpotential of Cu-bmpa. ${ }^{20}$ For $\mathbf{C u}_{3} \mathbf{L} \mathbf{1}$, this slight decrease of $0.06 \mathrm{~V}$ for the overpotential reflects the slight positive shift in the $E_{1 / 2}$ value of $0.07 \mathrm{~V} v s$. the RHE compared to $\mathbf{C u}$-bmpa. However, this is not the case for $\mathbf{C u}_{3} \mathbf{L} 2$; the slight decrease of $0.03 \mathrm{~V}$ for the overpotential does not reflect the large positive shift in the $E_{1 / 2}$ value of $0.20 \mathrm{~V} v s$. the RHE compared to Cu-bmpa.

The RRDE LSV data of $\mathrm{Cu}_{3} \mathbf{L} 1$ and $\mathrm{Cu}_{3} \mathrm{~L} 2$ show maximum catalytic disk current $\left(i_{\text {cat }}\right)$ values of 0.57 and $0.52 \mathrm{~mA}$ at -0.15 $\mathrm{V} v$ s. the RHE, respectively (Fig. 8). These values are similar to the reported $i_{\text {cat }}$ value of $0.57 \mathrm{~mA}$ for Cu-bmpa at $-0.15 \mathrm{~V} v s$. the RHE. $^{20}$ Just like for Cu-bmpa, an increase in the ring current is observed with decreasing applied disk potential for both $\mathbf{C u}_{3} \mathbf{L 1}$ and $\mathbf{C u}_{3} \mathbf{L} 2$. This indicates that both catalysts produce $\mathrm{H}_{2} \mathrm{O}_{2}$ along the entire potential window in which the ORR takes place.

To quantify the formation of $\mathrm{H}_{2} \mathrm{O}_{2}$ along the potential regime for ORR catalysis, the percentage of $\mathrm{H}_{2} \mathrm{O}_{2}$ produced during ORR catalysis $\left(\% \mathrm{H}_{2} \mathrm{O}_{2}\right)$ was determined according to the following equation:

$$
\% \mathrm{H}_{2} \mathrm{O}_{2}=\frac{2 \times\left(i_{\text {ring }} / N_{\mathrm{H}_{2} \mathrm{O}_{2}}\right)}{i_{\text {disk }}+\left(i_{\text {ring }} / N_{\mathrm{H}_{2} \mathrm{O}_{2}}\right)} \times 100 \%
$$

where $i_{\text {ring }}$ and $i_{\text {disk }}$ are the observed ring and disk current, respectively, and $\mathrm{N}_{\mathrm{H}_{2} \mathrm{O}_{2}}$ is the collection efficiency of the Pt ring for $\mathrm{H}_{2} \mathrm{O}_{2}$ (see the ESI $8.1 \dagger$ for a full derivation). ${ }^{69}$ This collection efficiency amounts to 0.125 as we have reported previously for the same RRDE setup. ${ }^{19}$

Fig. 9 shows the $\% \mathrm{H}_{2} \mathrm{O}_{2}$ values along the potential regime for ORR catalysis by $\mathbf{C u}_{3} \mathbf{L 1}$ and $\mathrm{Cu}_{3} \mathbf{L} 2$ obtained from the RRDE LSV data. For $\mathrm{Cu}_{3} \mathbf{L 1}$, the percentage of $\mathrm{H}_{2} \mathrm{O}_{2}$ produced during ORR catalysis remains relatively stable with a slight decrease from $\sim 76 \%$ near the ORR onset potential to $\sim 63 \%$ at $-0.15 \mathrm{~V}$ vs. the RHE (Fig. 9a). These values are comparable to the reported $\% \mathrm{H}_{2} \mathrm{O}_{2}$ values for $\mathbf{C u}$-bmpa. ${ }^{20}$ For $\mathbf{C u}_{3} \mathbf{L} 2$, the initial $\% \mathrm{H}_{2} \mathrm{O}_{2}$ of $\sim 58 \%$ near the ORR onset potential decreases more rapidly to $\sim 27 \%$ at $-0.15 \mathrm{~V}$ vs. the RHE (Fig. 9b). This
$\% \mathrm{H}_{2} \mathrm{O}_{2}$ value of $\sim 27 \%$ observed for $\mathrm{Cu}_{3} \mathbf{L} 2$ at $-0.15 \mathrm{~V}$ vs. the RHE is significantly lower than the observed $\% \mathrm{H}_{2} \mathrm{O}_{2}$ values for $\mathrm{Cu}_{3} \mathrm{L1}$ and Cu-bmpa.

Additionally, the values for $\% \mathrm{H}_{2} \mathrm{O}_{2}$ were determined by RRDE CA measurements as a function of time. These RRDE CA measurements were performed at applied disk potentials of $0.35,0.30,0.20$ and $0.0 \mathrm{~V}$ vs. the RHE for 5 minutes (ESI $8.3 \dagger)$. As shown in Fig. 9b, the $\mathrm{oH}_{2} \mathrm{O}_{2}$ values obtained from the RRDE CA data of $\mathbf{C u}_{3} \mathbf{L} 2$ correlate well with the values obtained from the RRDE LSV data. However, the $\% \mathrm{H}_{2} \mathrm{O}_{2}$ values obtained from the RRDE CA data of $\mathbf{C u}_{3} \mathbf{L 1}$ at applied disk potentials of 0.0 and $0.20 \mathrm{~V} v s$. the RHE are significantly lower than the values obtained from the RRDE LSV data (Fig. 9a). These observations are concomitant with an increase of the disk current and a decrease of the ring current over time during CA. This points to the formation of $\mathrm{Cu}^{0}$ at the electrode surface which catalyzes the 4-electron reduction of dioxygen, as we have observed previously for Cu-bmpa (ESI $8.3 \dagger) .{ }^{20}$ The involvement of $\mathrm{Cu}^{0}$ in the LSV experiments can be excluded on the basis of the aforementioned dipping and microbalance experiments (ESI $7 \dagger$ ). Overall, it can therefore be concluded that $\mathbf{C u}_{3} \mathbf{L 1}$ has a comparable product selectivity to Cu-bmpa, while $\mathbf{C u}_{3} \mathbf{L} 2$ has a much higher selectivity for the 4-electron process.

\section{$\mathrm{H}_{2} \mathrm{O}_{2}$ reduction behavior}

As discussed in the previous section, the RRDE LSV data of both $\mathrm{Cu}_{3} \mathbf{L} \mathbf{1}$ and $\mathrm{Cu}_{3} \mathbf{L} 2$ result in ${ }_{0} \mathrm{H}_{2} \mathrm{O}_{2}$ values above zero along the entire ORR active potential window. This means that both complexes do not catalyze the full four-electron ORR in the investigated potential window. However, since there is also no complete $\mathrm{H}_{2} \mathrm{O}_{2}$ selectivity, limitations seem to arise after the initial two-electron reduction of $\mathrm{O}_{2}$ to $\mathrm{H}_{2} \mathrm{O}_{2}$. Therefore, the $\mathrm{H}_{2} \mathrm{O}_{2}$ reduction behavior of both $\mathrm{Cu}_{3} \mathbf{L} 1$ and $\mathrm{Cu}_{3} \mathrm{~L} 2$ was investigated by performing rotating disk electrode (RDE) measurements in phosphate buffer containing $1.1 \mathrm{mM} \mathrm{H}_{2} \mathrm{O}_{2}$ (Fig. 10). The $\mathrm{H}_{2} \mathrm{O}_{2}$ concentration amounted to $1.1 \mathrm{mM}$ in order to
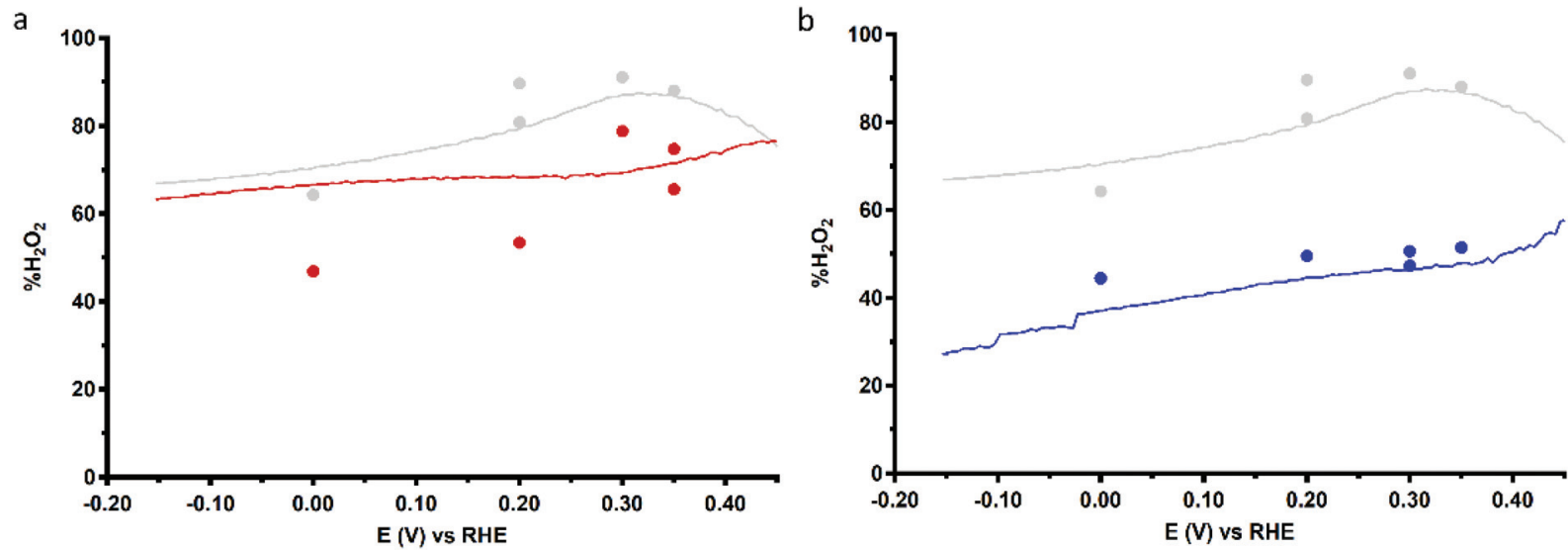

Fig. 9 Percentage of $\mathrm{H}_{2} \mathrm{O}_{2}$ produced during ORR catalysis $\left(\% \mathrm{H}_{2} \mathrm{O}_{2}\right)$ obtained from RRDE LSV (lines, $50 \mathrm{mV} \mathrm{s}{ }^{-1}$ ) and CA (dots) measurements as a function of applied disk potential for $0.1 \mathrm{mM} \mathrm{Cu} 3 \mathrm{L1}$ (a) and $\mathrm{Cu}_{3} \mathrm{~L} 2$ (b). The reference $\% \mathrm{H}_{2} \mathrm{O}_{2}$ values for $0.3 \mathrm{mM}$ Cu-bmpa are depicted in grey.

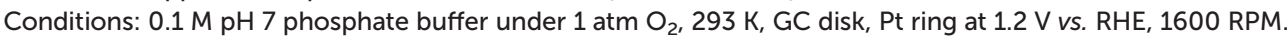




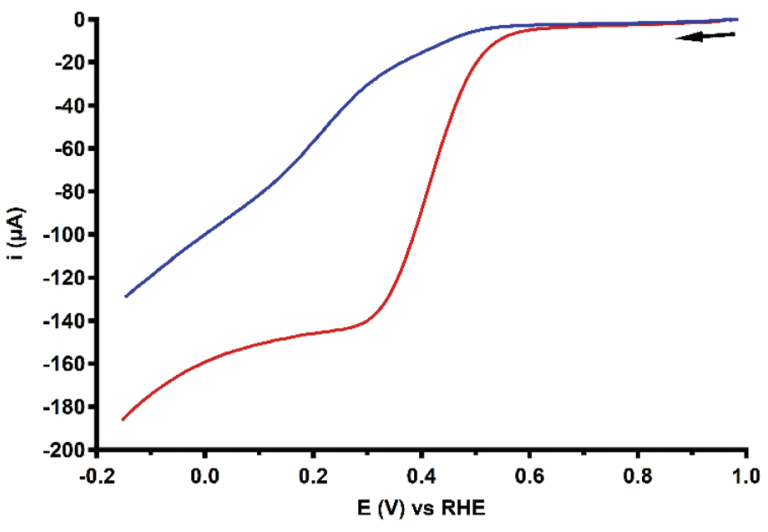

Fig. 10 RDE LSV curves of $0.1 \mathrm{mM} \mathrm{Cu}_{3} \mathrm{~L} 1$ (red) and $\mathrm{Cu}_{3} \mathrm{~L} 2$ (blue) in the presence of $1.1 \mathrm{mM} \mathrm{H}_{2} \mathrm{O}_{2}$ under $1 \mathrm{~atm}$ Ar. Conditions: $0.1 \mathrm{M} \mathrm{pH} 7$ phosphate buffer, $293 \mathrm{~K}, \mathrm{GC}$ disk, $1600 \mathrm{RPM}, 50 \mathrm{mV} \mathrm{s}^{-1}$ scan rate.

reproduce the concentration of $\mathrm{O}_{2}$ in $\mathrm{O}_{2}$ saturated $0.1 \mathrm{M} \mathrm{pH} 7$ phosphate buffer. $^{20,70-72}$

The $\mathrm{H}_{2} \mathrm{O}_{2}$ reduction profile obtained by RDE measurements for both $\mathbf{C u}_{3} \mathbf{L} \mathbf{1}$ and $\mathrm{Cu}_{3} \mathbf{L} \mathbf{2}$ did not show the presence of a mass-transport limiting current plateau between 1.0 and -0.15 $\mathrm{V} v$ s. the RHE, which we expect to find at $400 \mu \mathrm{A}$ according to the Levich equation (ESI 6.3†). This absence of a mass-transport limiting current plateau confirms that the $\mathrm{H}_{2} \mathrm{O}_{2}$ reduction by these trinuclear catalysts must be a relatively slow process, which was shown for Cu-bmpa and Cu-terpy previously as well. ${ }^{20,39}$

Upon addition of $1.1 \mathrm{mM} \mathrm{H} \mathrm{H}_{2} \mathrm{O}_{2}$ to the $\mathrm{Cu}_{3} \mathbf{L} 2$ solution in aqueous phosphate buffer, a change in the color and more specifically a change in the UV-Vis spectrum were observed (Fig. S13†). For the triethylbenzene ligand it has been observed previously that oxygen reactivity can induce an aromatic ligand hydroxylation reaction involving an NIH-shift of one of the ethyl substituents on the benzene spacer. ${ }^{41,42,50}$ To investigate if this is also induced by $\mathrm{H}_{2} \mathrm{O}_{2}$, the ligand was recovered from the complex upon treatment with a strong acid and EDTA to bind the free $\mathrm{Cu}$ ions after the exposure of $\mathbf{C u}_{3} \mathbf{L} 2$ to $\mathrm{H}_{2} \mathrm{O}_{2}$ (ESI $9.2 \dagger)$. Spectroscopy analysis does not suggest a shift of the ethyl substituent as was previously observed. The exact nature of the final structure could not be determined, but the absence of ligand oxidation for $\mathbf{C u}_{3} \mathbf{L 1}$ after the addition of $\mathrm{H}_{2} \mathrm{O}_{2}$ suggests that the benzylic ethyl- $\mathrm{CH}_{2}$ substituents of $\mathbf{L} 2$ are prone to oxidation upon exposure of $\mathbf{C u}_{3} \mathbf{L} 2$ to high concentrations of $\mathrm{H}_{2} \mathrm{O}_{2} \cdot{ }^{73}$

An overview of the electrochemical characteristics of $\mathrm{Cu}_{3} \mathbf{L} \mathbf{1}$, $\mathbf{C u}_{3} \mathbf{L} 2$ and Cu-bmpa is given in Table 1.

\section{Discussion}

There are four factors that have been considered during this work: the nature of the active species, the selectivity of the reaction, the efficiency of the $\mathrm{Cu}$-mediated ORR, and the catalytic stability of $\mathrm{Cu}_{3} \mathrm{L1}$ and $\mathrm{Cu}_{3} \mathrm{~L} 2$.
Table 1 Overview of the electrochemical characteristics of Cu-bmpa, $\mathrm{Cu}_{3} \mathrm{~L} 1$, and $\mathrm{Cu}_{3} \mathrm{~L} 2$

\begin{tabular}{llll}
\hline & $\mathbf{C u}-\mathbf{b m p a}^{20}$ & $\mathbf{C} \mathbf{u}_{3} \mathbf{L} \mathbf{1}$ & $\mathbf{C \mathbf { u } _ { 3 } \mathbf { L } 2}$ \\
\hline$E_{1 / 2}(\mathrm{~V} v s . \mathrm{RHE})$ & 0.30 & 0.37 & 0.50 \\
$\Delta E_{\mathrm{p}}(\mathrm{mV})$ & 56 & 105 & 90 \\
Diffusion coefficient $\left(\mathrm{cm}^{2} \mathrm{~s}^{-1}\right)$ & $2.1 \times 10^{-6}$ & $8.6 \times 10^{-7}$ & $4.8 \times 10^{-7}$ \\
$E_{\text {cat } / 2}(\mathrm{~V} v$ s. $\mathrm{RHE})$ & 0.37 & 0.37 & 0.33 \\
$\mathrm{RRDE}$ onset $(\mathrm{V} v$ s. $\mathrm{RHE})$ & 0.49 & 0.55 & 0.52 \\
$\% \mathrm{H}_{2} \mathrm{O}_{2}$ at onset & 75 & 76 & 58
\end{tabular}

\section{Active species}

The active species during the ORR catalysis by $\mathbf{C u}_{3} \mathbf{L 1}$ and $\mathrm{Cu}_{3} \mathrm{~L} 2$ are the reduced molecular species of these complexes. The deposition tests and RRDE experiments under Ar illustrate that both $\mathbf{C u}_{3} \mathbf{L} \mathbf{1}$ and $\mathbf{C u}_{3} \mathbf{L} 2$ do deposit on the electrode surface to some extent, yet that the activities of these deposits are negligible. This was confirmed by the low deposited mass found by the EQCM experiments. Also, during CA for several minutes under rotating conditions we did not see an increase of the catalytic activity, unless potentials below $0.2 \mathrm{~V}$ vs. RHE were applied. Under these conditions we see a clear build-up of $\mathrm{Cu}^{0}$, which is directly visualized by a decrease in $\% \mathrm{H}_{2} \mathrm{O}_{2}$ for $\mathrm{Cu}_{3} \mathbf{L} 1$ at these potentials, due to the 4-electron ORR on metallic copper. We do not see these effects in the LSV curves and at prolonged CA above $0.2 \mathrm{~V} v s$. the RHE for both complexes. The formation of substantial amounts of $\mathrm{Cu}^{0}$ requires time and negative potentials, which we have reported previously in a study concerning Cu-bmpa. ${ }^{20}$ It is therefore likely that the catalytic activity displayed in the LSV curves is due to the ORR mediated by the homogeneous active species of $\mathbf{C u}_{3} \mathbf{L 1}$ and $\mathrm{Cu}_{3} \mathbf{L} 2$.

\section{Selectivity}

During the ORR three reactions can occur, namely the direct 4-electron reduction of oxygen to water, the 2-electron reduction of oxygen to $\mathrm{H}_{2} \mathrm{O}_{2}$, and the subsequent reduction of $\mathrm{H}_{2} \mathrm{O}_{2}$ to water. ${ }^{19,39}$ During the direct 4-electron mechanism, no $\mathrm{H}_{2} \mathrm{O}_{2}$ is evolved, while $\mathrm{H}_{2} \mathrm{O}_{2}$ is formed as an obligatory intermediate in a $[2+2]$-stepwise mechanism.

Directly from the onset of the catalytic wave the determined $\% \mathrm{H}_{2} \mathrm{O}_{2}$ is significantly lower with $\mathbf{C u}_{3} \mathbf{L} 2$ compared to that with $\mathbf{C u}_{3} \mathbf{L} 1$ in the LSV RRDE experiments. In the case of $\mathbf{C u}-$ tmpa we have shown that the build-up of hydrogen peroxide is directly affected by the relative rates between the two electron reduction of dioxygen versus the reduction of hydrogen peroxide, and by their relative concentration near the electrode surface. ${ }^{19,39}$ In the case of Cu-tmpa this leads to a build-up of hydrogen peroxide, unless the oxygen reduction reaction becomes mass transport limited in oxygen. In the case of $\mathrm{Cu}_{3} \mathrm{~L} 1$ and $\mathrm{Cu}_{3} \mathrm{~L} 2$ mass transport limitations do not seem to play a role and consequently these catalysts produce hydrogen peroxide over the entire potential domain in the LSV curves. Whereas the oxygen reduction rates of $\mathbf{C u}_{3} \mathbf{L 1}$ and $\mathrm{Cu}_{3} \mathbf{L} \mathbf{2}$ are fairly similar, there appears to be a significant difference 
between the LSV curves of $\mathrm{Cu}_{3} \mathbf{L} 1$ and $\mathrm{Cu}_{3} \mathbf{L} 2$ in the presence of $\mathrm{H}_{2} \mathrm{O}_{2}$, with $\mathrm{Cu}_{3} \mathbf{L} 2$ being the slower catalyst (Fig. 10).

The slower $\mathrm{H}_{2} \mathrm{O}_{2}$ reduction by $\mathbf{C u}_{3} \mathbf{L} 2$ is inconsistent with the lower $\% \mathrm{H}_{2} \mathrm{O}_{2}$ observed for this catalyst, compared to $\mathbf{C u}$ bmpa and $\mathrm{Cu}_{3} \mathbf{L 1}$ (Fig. 9). This indicates that the selectivity must be due to other reasons besides the relative rates of the ORR versus the hydrogen peroxide reduction reaction (HPRR). In other words, $\mathbf{C u}_{3} \mathbf{L} 2$ must carry out the ORR in a different manner compared to $\mathrm{Cu}_{3} \mathbf{L} \mathbf{1}$ and $\mathbf{C u}$-bmpa. The low $\% \mathrm{H}_{2} \mathrm{O}_{2}$ for $\mathrm{Cu}_{3} \mathrm{~L} 2$ suggests that the selectivity is not a product from freely exchanging $\mathrm{H}_{2} \mathrm{O}_{2}$ from the coordination sphere of the trinuclear center, but instead must be due to a cooperative effect. Two modes of cooperation may occur. The cooperative effect might be caused by the trinuclear copper site at $\mathbf{C u}_{3} \mathbf{L} \mathbf{2}$ to operate in a similar manner to laccase and facilitate a direct 4-electron reduction reaction leading to a transformation of dioxygen to water without the intermediacy of hydrogen peroxide. However, since $\mathrm{H}_{2} \mathrm{O}_{2}$ is still formed along the entire measured potential regime, this is not likely to be the sole form of cooperation. Most likely the improved selectivity of $\mathbf{C u}_{3} \mathbf{L} 2$ towards the overall four electron reduction of dioxygen is that it is difficult for hydrogen peroxide to effectively dissociate from the trinuclear copper site of $\mathbf{C u}_{3} \mathbf{L} 2$, resulting in the alternating reduction of $\mathrm{O}_{2}$ and $\mathrm{H}_{2} \mathrm{O}_{2}$ at the catalytic site. We anticipate that this is an effect of the three $\mathrm{Cu}$ centers being positioned in close proximity to each other, making the probability of $\mathrm{H}_{2} \mathrm{O}_{2}$ to diffuse from the catalytic pocket lower.

\section{Efficiency}

Due to considerable uncertainty regarding the number of involved $\mathrm{Cu}$ centers during ORR catalysis performed by $\mathrm{Cu}_{3} \mathbf{L} \mathbf{1}$ and $\mathbf{C u}_{3} \mathbf{L} 2$, quantitative methods to determine the turnover frequencies of the catalysts such as the foot-of-the-wave analysis (FOWA) and the catalytic current enhancement methods cannot be performed without making substantial assumptions. $^{74-78}$ However, a qualitative description can be put forward by comparison of the RDE LSV profiles obtained during ORR catalysis. Specifically a comparison of the steepness of the ORR profiles provides more insight into the relative catalytic rate. The RDE LSV profiles for ORR catalysis performed by $\mathbf{C} \mathbf{u}_{3} \mathbf{L} \mathbf{1}, \mathbf{C u}_{3} \mathbf{L} \mathbf{2}$ and $\mathbf{C u}$-bmpa are depicted in Fig. 11. ${ }^{20}$ The reductive current for the ORR profile of $\mathrm{Cu}_{3} \mathbf{L 1}$ increases faster than for the ORR profile of $\mathrm{Cu}_{3} \mathbf{L} 2$, especially between the onset potential and $\sim 0.3 \mathrm{~V} v s$. the RHE. This indicates that the rate for ORR catalysis is higher for $C_{3} \mathbf{L 1}$. Additionally, a comparison with the RDE LSV profile for ORR catalysis performed by Cu-bmpa reveals a slower increase in the reductive current for the ORR profiles of the trinuclear catalysts compared to the mononuclear catalyst above $\sim 0.2 \mathrm{~V} v s$. the RHE. ${ }^{20}$ This indicates that the turnover frequencies of the trinuclear catalysts are substantially lower than those of the mononuclear systems reported previously. ${ }^{20}$

There are several possible explanations for the slow catalysis in these complexes. One reason might be found in the reorganization energy associated with the change of the oxidation state of the $\mathrm{Cu}$ ions. ${ }^{79,80}$ According to the Marcus theory the

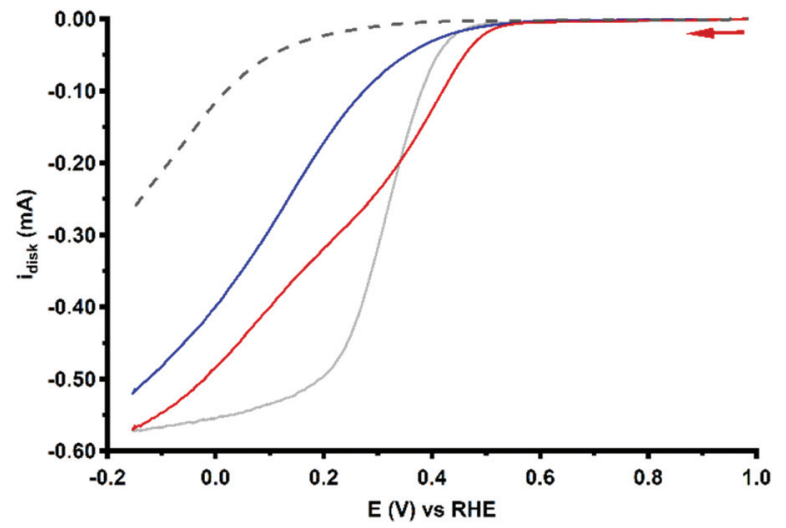

Fig. 11 RDE LSV curves of $0.1 \mathrm{mM} \mathrm{Cu}_{3} \mathrm{~L} 1$ (red) and $\mathrm{Cu}_{3} \mathrm{~L} 2$ (blue) under 1 atm $\mathrm{O}_{2}$ at 1600 RPM. The reference LSV curve of $0.3 \mathrm{mM} \mathrm{Cu-bmpa} \mathrm{is}$ depicted in grey. The reference voltammogram in the absence of the complex under 1 atm $\mathrm{O}_{2}$ is depicted as a grey dashed line. Conditions: $0.1 \mathrm{M} \mathrm{pH} 7$ phosphate buffer, $293 \mathrm{~K}, \mathrm{GC}$ disk, $50 \mathrm{mV} \mathrm{s}^{-1}$ scan rate.

rates of electron transfer reactions are affected by their accompanying reorganization energies. ${ }^{81}$ This largely relates to the ability of the ligands to accommodate the metal site at multiple oxidation states, and to switch between the different preferred geometries via facile transitions. It is therefore expected that slow electron transfer kinetics and consecutive slow ORR catalysis are the result of large structural reorganization barriers during the formation of the fully reduced state of $\mathbf{C u}_{3} \mathbf{L 1}$ and $\mathbf{C u}_{3} \mathbf{L} 2$. Due to the steric hindrance by the relatively close proximity of the $\mathbf{C u}-\mathbf{b m p a}$ sites of $\mathbf{C u}_{3} \mathbf{L} 2$ to one another compared to the Cu-bmpa sites of $\mathbf{C u}_{3} \mathbf{L 1}$, this effect is more pronounced in $\mathbf{C u}_{3} \mathbf{L}$ 2. The lower catalytic currents may also be caused by the lower diffusion rate of the trinuclear complexes compared to for example Cu-bmpa (Table 1). This results in a relatively low number of catalytic sites being reduced by the cathode compared to those in the case of catalysts with higher diffusion constants.

\section{Stability}

With UV-Vis spectroscopy we have shown that both $\mathbf{C u}_{3} \mathbf{L} \mathbf{1}$ and $\mathrm{Cu}_{3} \mathbf{L} 2$ are stable over prolonged time in a $0.1 \mathrm{M} \mathrm{pH} 7$ phosphate buffer. Moreover, the UV-Vis measurement results before and after ORR experiments remained unchanged. However, at high $\mathrm{H}_{2} \mathrm{O}_{2}$ concentration, the trinuclear complex $\mathbf{C u}_{3} \mathbf{L} 2$ suffers from intrinsic stability problems. It seems that in particular the ethylene functionalities that force all three copper sites towards the same plane of the aromatic node of L2 are susceptible towards intramolecular oxidation reactions in the presence of millimolar concentrations of hydrogen peroxide. ${ }^{82,83}$ However, this structural change for $\mathbf{C u}_{3} \mathbf{L} 2$ was only observed upon addition of large quantities of $\mathrm{H}_{2} \mathrm{O}_{2}$ and was not observed during ORR catalysis, where high concentrations of peroxide were avoided. Therefore, this structural change upon $\mathrm{H}_{2} \mathrm{O}_{2}$ addition is not expected to play a role in ORR catalysis. 


\section{Conclusions}

We have studied the effect of cooperativity between two or three copper sites on the catalytic activity and selectivity of the ORR. Although the catalytic currents are lower than those for freely rotating and diffusing single site complexes, our results show that the selectivity of the copper mediated ORR was significantly enhanced towards the overall 4-electron process due to a cooperative effect between three copper sites that have been positioned in close proximity.

\section{Conflicts of interest}

There are no conflicts to declare.

\section{Acknowledgements}

The authors gratefully acknowledge the Magnetism Competence Center at the Jean Lamour Institute in Nancy, France for the support during SQUID measurements.

Financial support was provided by the European Research Council (ERC starting grant 637556 Cu4Energy to D. G. H. H.).

\section{References}

1 D. G. Nocera, ChemSusChem, 2009, 2, 387-390.

2 A. Kirubakaran, S. Jain and R. K. Nema, Renewable Sustainable Energy Rev., 2009, 13, 2430-2440.

3 S. Shiva Kumar and V. Himabindu, Mater. Sci. Energy Technol., 2019, 2, 442-454.

4 C. Song and J. Zhang, in PEM Fuel Cell Electrocatalysts and Catalyst Layers, ed. J. Zhang, Springer, London, UK, 2008, pp. 89-134.

5 Z. W. Seh, J. Kibsgaard, C. F. Dickens, I. Chorkendorff, J. K. Nørskov and T. F. Jaramillo, Science, 2017, 355, eaad4998.

6 K. L. Hsueh, D. T. Chin and S. Srinivasan, J. Electroanal. Chem. Interfacial Electrochem., 1983, 153, 79-95.

7 Y. Wang, D. F. Ruiz Diaz, K. S. Chen, Z. Wang and X. C. Adroher, Mater. Today, 2020, 32, 178-203.

8 P. Giardina, V. Faraco, C. Pezzella, A. Piscitelli, S. Vanhulle and G. Sannia, Cell. Mol. Life Sci., 2010, 67, 369-385.

9 H. Komori and Y. Higuchi, J. Biochem., 2015, 158, 293-298.

10 E. I. Solomon, A. J. Augustine and J. Yoon, Dalton Trans., 2008, 1, 3921-3932.

11 S. M. Jones and E. I. Solomon, Cell. Mol. Life Sci., 2015, 72, 869-883.

12 M. R. Tarasevich, A. I. Yaropolov, V. A. Bogdanovskaya and S. D. Varfolomeev, J. Electroanal. Chem. Interfacial Electrochem., 1979, 104, 393-403.

13 V. Soukharev, N. Mano and A. Heller, J. Am. Chem. Soc., 2004, 126, 8368-8369.
14 M. S. Thorum, C. A. Anderson, J. J. Hatch, A. S. Campbell, N. M. Marshall, S. C. Zimmerman, Y. Lu and A. A. Gewirth, J. Phys. Chem. Lett., 2010, 1, 2251-2254.

15 M. J. Moehlenbrock and S. D. Minteer, Chem. Soc. Rev., 2008, 37, 1188-1196.

16 C. J. Cramer and W. B. Tolman, Acc. Chem. Res., 2007, 40, 601-608.

17 S. Kakuda, R. L. Peterson, K. Ohkubo, K. D. Karlin and S. Fukuzumi, J. Am. Chem. Soc., 2013, 135, 6513-6522.

18 S. Itoh, Acc. Chem. Res., 2015, 48, 2066-2074.

19 M. Langerman and D. G. H. Hetterscheid, Angew. Chem., Int. Ed., 2019, 58, 12974-12978.

20 N. W. G. Smits, B. van Dijk, I. de Bruin, S. L. T. Groeneveld, M. A. Siegler and D. G. H. Hetterscheid, Inorg. Chem., 2020, 59, 16398-16409.

21 H. Oh, S. Choi, J. Y. Kim, H. S. Ahn and S. Hong, Chem. Commun., 2019, 55, 12659-12662.

22 P. Vasudevan, Santosh, N. Mann and S. Tyagi, Transition Met. Chem., 1990, 15, 81-90.

23 S. Fukuzumi, H. Kotani, H. R. Lucas, K. Doi, T. Suenobu, R. L. Peterson and K. D. Karlin, J. Am. Chem. Soc., 2010, 132, 6874-6875.

24 M. S. Thorum, J. Yadav and A. A. Gewirth, Angew. Chem., Int. Ed., 2009, 48, 165-167.

25 G. A. Goenaga, A. Belapure, C. Zhang, A. Papandrew, S. Foister and T. Zawodzinski, ECS Trans., 2011, 41, 1193-1205.

26 M. Kato, N. Oyaizu, K. Shimazu and I. Yagi, J. Phys. Chem. C, 2016, 120, 15814-15822.

27 R. Venegas, K. Munoz-Becerra, L. Lemus, A. Toro-Labbe, J. H. Zagal and F. J. Recio, J. Phys. Chem. C, 2019, 123, 19468-19478.

28 J. Zhang and F. C. Anson, Electrochim. Acta, 1993, 38, 24232429.

29 C. C. L. McCrory, X. Ottenwaelder, T. D. P. Stack and C. E. D. Chidsey, J. Phys. Chem. A, 2007, 111, 12641-12650.

30 L. M. Mirica, X. Ottenwaelder and T. D. P. Stack, Chem. Rev., 2004, 104, 1013-1046.

31 E. A. Lewis and W. B. Tolman, Chem. Rev., 2004, 104, 10471076.

32 S. Hong, Y.-M. Lee, K. Ray and W. Nam, Coord. Chem. Rev., 2017, 334, 25-42.

33 C. E. Elwell, N. L. Gagnon, B. D. Neisen, D. Dhar, A. D. Spaeth, G. M. Yee and W. B. Tolman, Chem. Rev., 2017, 117, 2059-2107.

34 M. A. Thorseth, C. E. Tornow, E. C. M. Tse and A. A. Gewirth, Coord. Chem. Rev., 2013, 257, 130-139.

35 J. A. Halfen, S. Mahapatra, E. C. Wilkinson, S. Kaderli, V. G. Young, L. Que, A. D. Zuberbühler and W. B. Tolman, Science, 1996, 271, 1397.

36 B. van Dijk, J. P. Hofmann and D. G. H. Hetterscheid, Phys. Chem. Chem. Phys., 2018, 20, 19625-19634.

37 J. Serrano-Plana, I. Garcia-Bosch, A. Company and M. Costas, Acc. Chem. Res., 2015, 48, 2397-2406.

38 L. Tahsini, H. Kotani, Y.-M. Lee, J. Cho, W. Nam, K. D. Karlin and S. Fukuzumi, Chem. - Eur. J., 2012, 18, 1084-1093. 
39 M. Langerman and D. G. H. Hetterscheid, ChemElectroChem, 2021, 8, 2783-2791.

40 S. Fukuzumi, Y.-M. Lee and W. Nam, ChemCatChem, 2018, 10, 9-28.

41 K. D. Karlin, Q. F. Gan, A. Farooq, S. Liu and J. Zubieta, Inorg. Chem., 1990, 29, 2549-2551.

42 K. D. Karlin, Q.-F. Gan and Z. Tyeklár, Chem. Commun., 1999, 1, 2295-2296.

43 E. Y. Tsui, M. W. Day and T. Agapie, Angew. Chem., Int. Ed., 2011, 50, 1668-1672.

44 D. Maiti, J. S. Woertink, R. A. Ghiladi, E. I. Solomon and K. D. Karlin, Inorg. Chem., 2009, 48, 8342-8356.

45 D. Lionetti, M. W. Day and T. Agapie, Chem, 2013, 4, 785790.

46 E. C. M. Tse, D. Schilter, D. L. Gray, T. B. Rauchfuss and A. A. Gewirth, Inorg. Chem., 2014, 53, 8505-8516.

47 X. Engelmann, E. R. Farquhar, J. England and K. Ray, Inorg. Chim. Acta, 2018, 481, 159-165.

48 N. Thiyagarajan, D. Janmanchi, Y. F. Tsai, W. H. Wanna, R. Ramu, S. I. Chan, J. M. Zen and S. S. F. Yu, Angew. Chem., Int. Ed., 2018, 57, 3612-3616.

49 E. Salvadeo, L. Dubois and J.-M. Latour, Coord. Chem. Rev., 2018, 374, 345-375.

50 H. Ohi, Y. Tachi and S. Itoh, Inorg. Chem., 2006, 45, 1082510835.

51 E. C. Brown, B. Johnson, S. Palavicini, B. E. Kucera, L. Casella and W. B. Tolman, Dalton Trans., 2007, 1, 3035-3042.

52 A. M. Geer, C. Musgrave Iii, C. Webber, R. J. Nielsen, B. A. McKeown, C. Liu, P. P. M. Schleker, P. Jakes, X. Jia, D. A. Dickie, J. Granwehr, S. Zhang, C. W. Machan, W. A. Goddard and T. B. Gunnoe, ACS Catal., 2021, 11, 7223-7240.

53 K. D. Karlin, Q. F. Gan, A. Farooq, S. Liu and J. Zubieta, Inorg. Chem., 1990, 29, 2549-2551.

54 C. Walsdorff, S. Park, J. Kim, J. Heo, K.-M. Park, J. Oh and K. Kim, Dalton Trans., 1999, 1, 923-930.

55 M. Komiyama, S. Kina, K. Matsumura, J. Sumaoka, S. Tobey, V. M. Lynch and E. Anslyn, J. Am. Chem. Soc., 2002, 124, 13731-13736.

56 Y. Zhao, J. Zhu, W. He, Z. Yang, Y. Zhu, Y. Li, J. Zhang and Z. Guo, Chem. - Eur. J., 2006, 12, 6621-6629.

57 N. F. Chilton, R. P. Anderson, L. D. Turner, A. Soncini and K. S. Murray, J. Comput. Chem., 2013, 34, 1164-1175.

58 Z. Boulsourani, V. Tangoulis, C. P. Raptopoulou, V. Psycharis and C. Dendrinou-Samara, Dalton Trans., 2011, 40, 7946-7956.

59 D. J. Iverson, G. Hunter, J. F. Blount, J. R. Damewood and K. Mislow, J. Am. Chem. Soc., 1981, 103, 6073-6083.

60 J. C. Barnes, J. A. Chudek, G. Hunter, A. J. Blake, P. J. Dyson, B. F. G. Johnson and W. Weissensteiner, J. Chem. Soc., Faraday Trans., 1995, 91, 2149-2153.
61 V. Marks, H. E. Gottlieb, A. Melman, G. Byk, S. Cohen and S. E. Biali, J. Org. Chem., 2001, 66, 6711-6718.

62 W. Weissensteiner, A. Gutierrez, M. D. Radcliffe, J. Siegel, M. D. Singh, P. J. Tuohey and K. Mislow, J. Org. Chem., 1985, 50, 5822-5827.

63 S. Choksakulporn, A. Punkvang and Y. Sritana-Anant, J. Mol. Struct., 2015, 1082, 97-102.

64 N. Elgrishi, K. J. Rountree, B. D. McCarthy, E. S. Rountree, T. T. Eisenhart and J. L. Dempsey, J. Chem. Educ., 2018, 95, 197-206.

65 M. J. Powers and T. J. Meyer, J. Am. Chem. Soc., 1978, 100, 4393-4398.

66 J. E. Sheats, R. S. Czernuszewicz, G. C. Dismukes, A. L. Rheingold, V. Petrouleas, J. Stubbe, W. H. Armstrong, R. H. Beer and S. J. Lippard, J. Am. Chem. Soc., 1987, 109, 1435-1444.

67 M. M. Morrison and D. T. Sawyer, J. Am. Chem. Soc., 1977, 99, 257-258.

68 R. Lomoth, P. Huang, J. Zheng, L. Sun, L. Hammarström, B. Åkermark and S. Styring, Eur. J. Inorg. Chem., 2002, 2002, 2965-2974.

69 R. Zhou, Y. Zheng, M. Jaroniec and S.-Z. Qiao, ACS Catal., 2016, 6, 4720-4728.

70 A. Schumpe, I. Adler and W.-D. Deckwer, Biotechnol. Bioeng., 1978, 20, 145-150.

71 D. Tromans, Ind. Eng. Chem. Res., 2000, 39, 805-812.

72 W. Xing, M. Yin, Q. Lv, Y. Hu, C. Liu and J. Zhang, Rotating Electrode Methods and Oxygen Reduction Electrocatalysts, Elsevier, Amsterdam, 2014, pp. 1-31.

73 M. M. Rahman, M. G. Ara, M. S. Rahman, M. S. Uddin, M. N. Bin-Jumah and M. M. Abdel-Daim, J. Nanomater., 2020, 2020, 1-20.

74 C. Costentin, S. Drouet, M. Robert and J. M. Saveant, J. Am. Chem. Soc., 2012, 134, 19949-19950.

75 E. S. Rountree, B. D. McCarthy, T. T. Eisenhart and J. L. Dempsey, Inorg. Chem., 2014, 53, 9983-10002.

76 C. Costentin and J. M. Saveant, ChemElectroChem, 2014, 1, 1226-1236.

77 D. J. Wasylenko, C. Rodriguez, M. L. Pegis and J. M. Mayer, J. Am. Chem. Soc., 2014, 136, 12544-12547.

78 A. M. Appel and M. L. Helm, ACS Catal., 2014, 4, 630-633.

79 E. Garribba and G. Micera, J. Chem. Educ., 2006, 83, 12291232.

80 E. W. Dahl and N. K. Szymczak, Angew. Chem., Int. Ed., 2016, 55, 3101-3105.

81 R. A. Marcus, Rev. Mod. Phys., 1993, 65, 599-610.

82 S. Mahapatra, V. G. Young, S. Kaderli, A. D. Zuberbuhler and W. B. Tolman, Angew. Chem., Int. Ed. Engl., 1997, 36, 130-133.

83 S. Mahapatra, J. A. Halfen and W. B. Tolman, J. Am. Chem. Soc., 1996, 118, 11575-11586. 